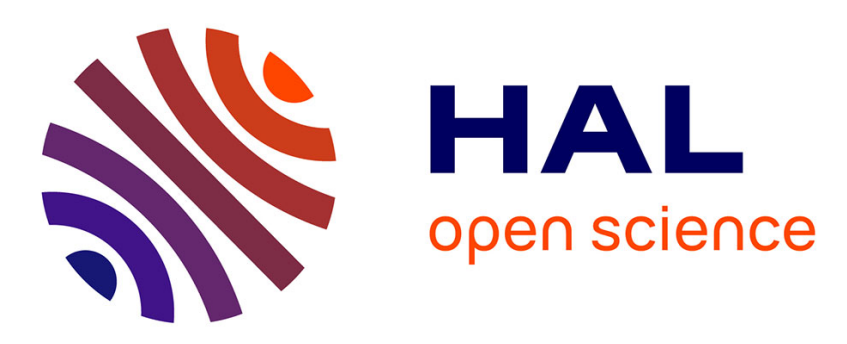

\title{
The Welfare Gains of Trade Integration in the European Monetary Union
}

Stéphane Auray, Aurélien Eyquem, Jean-Christophe Poutineau

\section{To cite this version:}

Stéphane Auray, Aurélien Eyquem, Jean-Christophe Poutineau. The Welfare Gains of Trade Integration in the European Monetary Union. 2009. halshs-00464213

\section{HAL Id: halshs-00464213 \\ https://shs.hal.science/halshs-00464213}

Submitted on 16 Mar 2010

HAL is a multi-disciplinary open access archive for the deposit and dissemination of scientific research documents, whether they are published or not. The documents may come from teaching and research institutions in France or abroad, or from public or private research centers.
L'archive ouverte pluridisciplinaire HAL, est destinée au dépôt et à la diffusion de documents scientifiques de niveau recherche, publiés ou non, émanant des établissements d'enseignement et de recherche français ou étrangers, des laboratoires publics ou privés. 


\section{DOCUMENTS DE TRAVAIL - WORKING PAPERS}

$$
\text { W.P. 09-27 }
$$

\section{The Welfare Gains of Trade Integration in the European Monetary Union}

Stéphane Auray, Aurélien Eyquem, Jean-Christophe Poutineau

Décembre 2009

GATE Groupe d'Analyse et de Théorie Économique UMR 5824 du CNRS

93 chemin des Mouilles - 69130 Écully - France

B.P. $167-69131$ Écully Cedex

Tél. +33 (0)4 72866060 - Fax +33 (0)4 72866090

Messagerie électronique gate@gate.cnrs.fr

Serveur Web : www.gate.cnrs.fr 


\title{
The Welfare Gains of Trade Integration in the European Monetary Union *
}

\author{
Stéphane Auray ${ }^{\mathrm{a}, *}$, Aurélien Eyquem ${ }^{\mathrm{b}}$, Jean-Christophe Poutineau ${ }^{\mathrm{b}}$ \\ ${ }^{\mathrm{a}}$ GREMARS, Unversité de Lille 3 and CIRPEE, Maison de la Recherche, Domaine \\ Universitaire du Pont de Bois, BP 149, 59653 Villeneuve d'Ascq cedex, France \\ ${ }^{\mathrm{b}}$ CREM, Université de Rennes 1, 7, place Hoche, 35065 Rennes Cedex, France
}

First Version: June 2006. This version: January 2009

\begin{abstract}
This paper evaluates the welfare gains arising from a deeper trade integration in the European Monetary Union. To do this, the European Monetary Union is represented in a realistic way by an intertemporal general equilibrium model with incomplete financial markets, sticky prices and home bias both in private consumption and production. The model is estimated and globally not rejected by the data. Two main results emerge : (i) an increase in vertical (intermediate goods) trade implies welfare gains while (ii) an increase in horizontal trade implies welfare losses.
\end{abstract}

Keywords: trade integration, inflation differentials, welfare analysis, optimal currency areas.

J.E.L. Classification: F32, F41, F47.

\section{Introduction}

This article investigates the welfare effects of a deeper horizontal or vertical trade integration in the European Monetary Union (EMU). Independently of its long-run consequences, welfare gains of trade integration usually rest upon the increased correlation of business cycles and the improved overall adequacy of the common monetary

ऋ We would like to thank James Anderson, as well as participants of the ESEM in Budapest, the RIEF Meeting in Rome, and the 24th Symposium in Money, Banking and Finance in Rennes for helpful comments. The traditional disclaimer applies.

* Corresponding author. Email: stephane.auray@univ-lille3.fr 
policy to national situations. This paper shows that the impact of trade integration is more contrasted when assuming that financial markets are incomplete and imperfectly integrated.

We lay out an estimated two-country DSGE model of the European Monetary Union (EMU) that accounts for the imperfect integration of both goods and financial markets. As in Ricci (1997), the model encompasses real and monetary arguments for the costs of conducting a single monetary policy in a monetary union characterized by business cycles asymmetries and inflation differentials. Indeed, the model features home bias in private consumption and production technology, incomplete and imperfectly integrated private financial markets, Calvo type sticky prices, and i.i.d. productivity and public spending shocks. These assumptions are also set up to be consistent with the current economic situation of the EMU, characterized by persistent asymmetries in business cycles and significant inflation differentials (see Camacho, Perez-Quiros and Saiz, 2006 and Lane, 2006 for discussions).

In this tractable framework, asymmetric shocks and/or shocks imply asymmetries in business cycles and inflation differentials that can not be addressed by the central bank of the monetary union. These business cycles asymmetries and inflation differentials translate into welfare costs, building on two mains sources: nominal inertia and imperfect risk-sharing combined to a costly access to financial markets. The role of nominal inertia in a monetary union, as well as means to reduce the associated costs, have already been extensively studied in the literature (see among others Bengino, 2004; Beetsma and Jensen, 2005 and Gali and Monacelli, 2008). Less attention has been paid to welfare losses related to imperfectly integrated financial markets in a monetary union. In line with Carré and Collard (2003), we show that imperfect risk-sharing crucially affects the welfare costs of business cycles asymmetries and the size, sign and structure of welfare gains generated by trade integration.

First, we show that an increase of horizontal or vertical trade integration, modeled as a reduction of home bias in consumption or in production, increases the correlation of business cycles through an increase of mutual trade flows. The overall adequacy of the common monetary policy to national situations is thus clearly improved. The volatility of national inflation rates decreases, which significantly improves the aggregate welfare in the monetary union. These results are in the spirit of those of Romer (1993), but the mechanisms that lead to these effects are different. ${ }^{1}$

Second, vertical and horizontal trade have opposite effects on the pattern of external adjustment to asymmetric shocks. Vertical trade integration reduces the overall need for external adjustment, i.e. the volatility of the current account while horizontal trade increases it. Because financial markets are incomplete and imperfectly integrated, a higher (respectively lower) volatility of the current account increases (respectively

$\overline{1}$ According to Romer, loose monetary policies become less appealing when openness increases. 
dampens) the welfare costs related to the imperfect integration of financial markets and imperfect risk-sharing.

The result builds on the following mechanism. Using financial markets (the current account) more intensively to smooth their wealth over time, households increase (respectively decrease) their labor supply when contracting debts (respectively accumulating assets) to respect their intertemporal budget constraint. Since we consider a closed monetary union, debts contracted by the representative household of a country are necessarily equal to the cumulated assets of the representative household of the other country. As a result, increased movements of the current account are met by opposite changes in labor supplies. In the equilibrium, the distance of relative hours, relative wages and intermediate terms-of-trade to their natural equilibrium path (characterized by complete financial markets) increases, which generates welfare losses. The welfare gains of vertical trade integration are consequently reinforced, while the welfare gains of horizontal trade integration are reduced or turn into welfare losses, depending on parameterizations.

Quantitatively speaking, we highlight that vertical trade integration leads to important welfare gains for the whole range of possible parameters of the model. In the baseline estimation, we show that a $10 \%$ increase $^{2}$ of vertical trade implies an average welfare gain equivalent to a $12.76 \%$ rise of permanent consumption for a constant labor effort. On the other hand, horizontal trade generates lower welfare gains or welfare losses, depending on the parametrization. In the baseline estimation, a $10 \%$ increase of horizontal tarde implies an average welfare loss equivalent to a $2.09 \%$ drop of permanent consumption. A sensitivity analysis shows that horizontal trade can lead to welfare gains, especially when the welfare costs of nominal rigidities increase or when the welfare costs of imperfect financial integration decrease.

The remaining of the paper is organized as follows. Section 2 describes a two-country model of an imperfectly integrated monetary union. Based on EMU data, Section 3 provides estimates for the structural parameters of the log-linear approximation of the model. The dynamics properties of the model are analyzed in Section 4. Section 5 provides an extensive welfare analysis of an increase in trade integration and presents some sensitivity analysis. A last section offers some concluding remarks.

\section{An imperfectly integrated monetary union}

The model describes a two-country world with a common currency. Each nation represents half of this monetary union. It is populated by $N$ infinitely-living households, a government, firms producing intermediate and final goods, and importers assembling

2 This increase fits the actual consensus concerning the effect of the EMU on intrazone trade (see Baldwin, 2006). 
consumption goods. All goods are traded. Monetary policy is delegated to the central bank of the monetary union which controls the interest rate. The international financial market is incomplete and agents only trade one-period composite bonds. ${ }^{3}$

\subsection{Households and national governments}

In each country the number of infinitely-living households is normalized to one. The representative household $j \in[0,1]$ of nation $i \in\{h, f\}$ maximizes a welfare index,

$$
\sum_{t=0}^{\infty} \beta^{t} E_{0}\left\{\frac{C_{t}^{i}(j)^{1-\sigma}}{1-\sigma}-\frac{N_{t}^{i}(j)^{1+\psi}}{1+\psi}\right\},
$$

subject to,

$$
B_{t+1}^{i}(j)-R_{t} B_{t}^{i}(j)=W_{t}^{i} N_{t}^{i}(j)+\Pi_{t}^{i}(j)-P_{t}^{i} C_{t}^{i}(j)-T_{t}^{i}(j)-P_{i, t} A C_{t}^{i}(j),
$$

and the following transversality condition,

$$
\lim _{T \rightarrow \infty} \prod_{s=t}^{T} R_{s}^{-1} E_{t}\left\{B_{T+1}^{i}(j)\right\}=0 .
$$

In Eq. (1), the subjective discount factor, $\beta$, is equal to $(1+\delta)^{-1}, \sigma$ is the intertemporal elasticity of substitution of private consumption and $\psi$ is the inverse of the Frisch elasticity. The aggregate consumption bundle of agent $(j)$ in country $i$ is called $C_{t}^{i}(j)$ and the quantity of labor that this agent supplies on the labor market $N_{t}^{i}(j)$. Money holdings are not introduced in the utility function since the money market plays no role for the dynamics when the nominal interest rate is the monetary policy instrument (see Beetsma and Jensen, 2005).

In Eq. $(2), B_{t}^{i}(j)$ is the amount of one-period nominal bonds hold by the representative agent of country $i$ at the end of period $t-1$, that pays a gross nominal rate of interest $R_{t}$ between periods $(t-1)$ and $t$. The consumer price index (CPI) in country $i$ is called $P_{t}^{i}$ while $P_{i, t}$ corresponds to the producer price index (PPI) in country $i . W_{t}^{i}$ is the nominal wage in country $i$ in period $t, \Pi_{t}^{i}(j)=\int_{0}^{1} \Pi_{t}^{i}(k, j) d k$ is the amount of profits paid by monopolistic final goods producers, and $T^{i}(j)$ is a lump-sum transfer. Finally, in the budget constraint, $A C_{t}^{i}(j)$ is a quadratic portfolio adjustment cost that households have to pay to financial intermediaries to access financial markets. The cost is defined according to,

$$
A C_{t}^{i}(j)=\frac{\chi}{2}\left[B_{t+1}^{i}(j)-B^{i}(j)\right]^{2},
$$

3 Nominal exchange rate issues per se as well as the analysis of the conditions underlying the adoption of a common currency are beyond the scope of the paper. 
where $B^{i}(j)$ is the steady state level of net foreign assets. The Euler condition that solves Eqs. (1)-(2) is affected by portfolio adjustment costs since,

$$
\frac{\beta R_{t+1}}{1+\chi P_{i, t}\left(B_{t+1}^{i}(j)-B^{i}(j)\right)} E_{t}\left\{\frac{P_{t}^{i} C_{t}^{i}(j)^{\sigma}}{P_{t+1}^{i} C_{t+1}^{i}(j)^{\sigma}}\right\}=1 .
$$

The portfolio adjustment cost parameter $(\chi)$ affects the sensitivity of wealth's accumulation to a variation of the interest rate, as it becomes more or less costly to smooth consumption by accessing financial markets. For instance, when $\chi$ decreases, it is less costly for the households to access to the financial markets. The labor supply function is based on the traditional consumption/leisure arbitrage,

$$
N_{t}^{i}(j)^{\psi} C_{t}^{i}(j)^{\sigma}=\frac{W_{t}^{i}}{P_{t}^{i}}
$$

\subsection{Governments}

Governments choose the amount of public spending on the final goods market and balance their budget using lump-sum transfers. The budget constraint of the government is given by,

$$
\int_{0}^{1} T^{i}(j) d j+\tau \int_{0}^{1} P_{i, t}(k) Y_{t}^{i}(k) d k=P_{i, t} G_{t}^{i},
$$

where $\tau$ is a proportional subsidy to firms. Mixing monopolistic competition and Calvo staggered price contracts on final goods markets introduces several distortions with respect to the Pareto efficient equilibrium. Nominal rigidities imply inefficient fluctuations of both equilibrium inflation and output while the assumption of monopolistic competition affects the steady state. While monetary and/or fiscal policy may address the first issue, an optimal subsidy $\tau$ is able to address the second issue and restores the first-best allocation in the steady state (see Benigno and Woodford, 2005).

National public spending are entirely home biased, i.e.,

$$
G_{t}^{i}=\left[\int_{0}^{1} G_{t}^{i}(k)^{\frac{\theta-1}{\theta}} d k\right]^{\frac{\theta}{\theta-1}}
$$

where the level of aggregate public spending evolves according to,

$$
G_{t+1}^{i}=\left(1-\rho_{g}\right) G^{i}+\rho_{g} G_{t}^{i}+\zeta_{g, t+1}^{i}
$$

where $\zeta_{g, t}^{i}$ is an i.i.d. innovation. 


\subsection{Firms}

\subsubsection{Intermediate goods producers}

The production of final goods consists in a two-step process. First, in each country $i$, a continuum of identical firms (normalized to one) produce the same intermediate good and sell it on on a competitive market. The production function of these firms is given by,

$$
X_{t}^{i}=A_{t}^{i} L_{t}^{i}
$$

where $L_{t}^{i}$ is the labor demand and $A_{t}^{i}$ is the level of labor productivity evolving according to,

$$
A_{t+1}^{i}=\left(1-\rho_{a}\right) A^{i}+\rho_{a} A_{t}^{i}+\zeta_{a, t+1}^{i} .
$$

where $\zeta_{a, t}^{i}$ is an i.i.d. innovation.

\subsubsection{Final goods producers}

Second, intermediate goods are traded within the monetary union and combined by monopolistic final goods producers $k \in[0,1]$. Intermediate goods are sold at their marginal cost $W_{t}^{i} / A_{t}^{i}$ and intermediate terms-of-trade are,

$$
\Sigma_{t}=\frac{W_{t}^{f} / A_{t}^{f}}{W_{t}^{h} / A_{t}^{h}} .
$$

The production function of final goods producer $k$ located in country $i$ is given by,

$$
Y_{t}^{i}(k)=\left[\left(1-\gamma_{i}\right)^{\frac{1}{\phi}} X_{h, t}^{i}(k)^{\frac{\phi-1}{\phi}}+\left(\gamma_{i}\right)^{\frac{1}{\phi}} X_{f, t}^{i}(k)^{\frac{\phi-1}{\phi}}\right]^{\frac{\phi}{\phi-1}} \text {. }
$$

In this expression, $X_{h, t}^{i}(k)$ is the consumption of intermediate goods produced in country $h$ of firm $k$ located in country $i$. The parameter $\left(1-\gamma_{i}\right) \in\left[0, \frac{1}{2}\right]$ is the home bias in the production of final goods. In the production function $(5), \phi$ is the elasticity of substitution between intermediate goods. The companion nominal marginal cost of firm $k$ in country $i, M C_{t}^{i}(k)$, is given by,

$$
M C_{t}^{i}(k)=\left[\left(1-\gamma_{i}\right)\left(W_{t}^{h} / A_{t}^{h}\right)^{1-\phi}+\left(\gamma_{i}\right)^{\frac{1}{\phi}}\left(W_{t}^{f} / A_{t}^{f}\right)^{1-\phi}\right]^{\frac{1}{1-\phi}}
$$

Final goods prices are governed by standard Calvo contracts. Each period, only a fraction $\left(1-\eta^{i}\right)$ of randomly selected firms located in country $i \in\{h, f\}$ are allowed to set new prices. Assuming that firms do not discriminate among markets they adress, 
these firms choose the following optimal price $\bar{P}_{i, t}(k)$,

$$
\bar{P}_{i, t}(k)=\frac{\theta}{(\theta-1)(1-\tau)} \frac{\sum_{v=0}^{\infty}\left(\eta^{i} \beta\right)^{v} E_{t}\left\{\frac{Y_{t+v}^{i}(k) M C_{t+v}^{i}}{P_{t+v}^{i} C_{t+v}^{i}(j)^{\sigma}}\right\}}{\sum_{v=0}^{\infty}\left(\eta^{i} \beta\right)^{v} E_{t}\left\{\frac{Y_{t+v}^{i}(k)}{P_{t+v}^{i} C_{t+v}^{i}(j)^{\sigma}}\right\}} .
$$

Aggregating among final firms and assuming behavioral symmetry of monopolistic producers, the average producer price level of final goods in country $i \in\{h, f\}$ is,

$$
P_{i, t}=\left[\left(1-\eta^{i}\right) \bar{P}_{i, t}(k)^{1-\theta}+\eta^{i} P_{i, t-1}^{1-\theta}\right]^{\frac{1}{1-\theta}} .
$$

\subsubsection{Importers}

A continuum of importers build units of consumption goods $\varrho$ using domestic and foreign final goods according the following production function,

$$
Z_{t}^{i}(\varrho)=\left[\left(1-\alpha_{i}\right)^{\frac{1}{\mu}}\left(\int_{0}^{1} Z_{h, t}^{i}(\varrho, k)^{\frac{\theta-1}{\theta}} d k\right)^{\frac{\theta(\mu-1)}{\mu(\theta-1)}}+\alpha_{i}^{\frac{1}{\mu}}\left(\int_{0}^{1} Z_{f, t}^{i}(\varrho, k)^{\frac{\theta-1}{\theta}} d k\right)^{\frac{\theta(\mu-1)}{\mu(\theta-1)}}\right]^{\frac{\mu}{\mu-1}},
$$

and sell them on perfectly competitive markets at the following price,

$$
P_{t}^{i}(\varrho)=P_{t}^{i}=\left[\left(1-\alpha_{i}\right)^{\frac{1}{\mu}}\left(\int_{0}^{1} P_{h, t}(k)^{1-\theta} d k\right)^{\frac{1-\mu}{1-\theta}}+\alpha_{i}^{\frac{1}{\mu}}\left(\int_{0}^{1} P_{f, t}(k)^{1-\theta} d k\right)^{\frac{1-\mu}{1-\theta}}\right]^{\frac{1}{1-\mu}},
$$

or equivalently,

$$
P_{t}^{i}=\left[\left(1-\alpha_{i}\right)^{\frac{1}{\mu}}\left(P_{h, t}\right)^{1-\mu}+\alpha_{i}^{\frac{1}{\mu}}\left(P_{f, t}\right)^{1-\mu}\right]^{\frac{1}{1-\mu}}
$$

In these expressions, $\left(1-\alpha_{i}\right) \in\left[0, \frac{1}{2}\right]$ is the home bias in the production of consumption goods, $\theta \geq 1$ is the elasticity of substitution among national varieties and $\mu$ is the elasticity of susbtitution between domestic and foreign final goods. Finally, we define final terms-of-trade in the monetary union as,

$$
S_{t}=\frac{P_{f, t}}{P_{h, t}}
$$

It has now become standard to regard home bias parameters, such as $1-\alpha_{i}$ or $1-\gamma_{i}$ as a relevant measures of goods market openness. Indeed, in equilibrium, $\alpha_{i}$ and $\gamma_{i}$ are the share of imported goods in the production of final and consumption goods respectively (see Corsetti, 2006 and Galí and Monacelli, 2005). In the remainder of the paper, we thus consider $\alpha_{i}$ and $\gamma_{i}$ directly as parameters measuring horizontal and vertical trade openness. 


\subsection{Monetary policy}

A common central bank controls the nominal interest rate within the monetary union,

$$
R_{t+1}=\left(1-\rho_{r}\right) R+\rho_{r} R_{t}+\varphi\left(\pi_{t}^{u}-\pi^{u}\right)
$$

where $\pi_{t}^{u}=\frac{1}{2} \pi_{t}^{h}+\frac{1}{2} \pi_{t}^{f}$ and $\pi_{t}^{i}=P_{t}^{i} / P_{t-1}^{i}$. This rule is commonly used in the literature (see among others Taylor, 1993; Clarida, Galí and Gertler, 1998 and Rudebusch and Svensson, 1999). Furthermore, it is a fair approximation of the monetary policy of the European Central Bank with respect to its mission, i.e. the stabilization of aggregate inflation in the EMU. Finally, a large empirical literature highlights the smoothness of the nominal interest rate variations in the euro area (see among others Peersman and Smets, 1999 and Gerlach and Schnabel, 2000).

\subsection{Markets equilibrium}

We solve the model assuming that each country is the mirror image of the other on the goods market. Posing $\alpha_{h}=\alpha$ and $\gamma_{h}=\gamma$ we simply get $\alpha_{f}=(1-\alpha)$ and $\gamma_{f}=(1-\gamma)$.

A competitive equilibrium is defined as a sequence of quantities,

$$
\left\{\mathcal{Q}_{t}\right\}_{t=0}^{\infty}=\left\{C_{t}^{h}, C_{t}^{f}, N_{t}^{h}, N_{t}^{f}, Y_{t}^{h}, Y_{t}^{f}, Z_{t}^{h}, Z_{t}^{f}, L_{t}^{h}, L_{t}^{f}, B_{t+1}^{h}, B_{t+1}^{f}, A C_{t}^{h}, A C_{t}^{f}\right\},
$$

and a sequence of prices,

$$
\left\{\mathcal{P}_{t}\right\}_{t=0}^{\infty}=\left\{\bar{P}_{h, t}(k), \bar{P}_{f, t}(k), P_{h, t}, P_{f, t}, P_{t}^{h}, P_{t}^{f}, W_{t}^{h}, W_{t}^{f}, R_{t+1}\right\},
$$

such that:

(i) For a given sequence of exogenous shocks $\left\{\mathcal{S}_{t}\right\}_{t=0}^{\infty}=\left\{A_{t}^{h}, A_{t}^{f}, G_{t}^{h}, G_{t}^{f}\right\}$ and prices $\left\{\mathcal{P}_{t}\right\}_{t=0}^{\infty},\left\{\mathcal{Q}_{t}\right\}_{t=0}^{\infty}$ respects households first order conditions and maximizes the profits of consumption, final and intermediate goods producers.

(ii) For a given sequence of shocks $\left\{\mathcal{S}_{t}\right\}_{t=0}^{\infty}$ and quantities $\left\{\mathcal{Q}_{t}\right\}_{t=0}^{\infty},\left\{\mathcal{P}_{t}\right\}_{t=0}^{\infty}$ clears consumption, final and intermediate goods markets, labor markets,

$$
N_{t}^{i}=\int_{0}^{1} N_{t}^{i}(j) d j=L_{t}^{i},
$$

and financial markets,

$$
\int_{0}^{1} B_{t}^{h}(j) d j+\int_{0}^{1} B_{t}^{f}(j) d j=0 .
$$

In the equilibrium, net foreign assets evolve as follows,

$$
B_{t+1}^{h}-B_{t}^{h}=\left(R_{t}-1\right) B_{t}^{h}+\alpha\left(P_{t}^{f} C_{t}^{f}-P_{t}^{h} C_{t}^{h}\right)+\gamma\left(M C_{t}^{f} Y_{t}^{f} D P_{t}^{f}-M C_{t}^{h} Y_{t}^{h} D P_{t}^{h}\right),
$$


where $D P_{t}^{i}$ is the dispersion of final goods production prices in country $i$.

\section{Estimation}

We estimate the log-linear version of the model using the Simulated Method of Moments (SMM) of Hansen (1982). ${ }^{4}$ In the symmetric competitive flexible price steady state, we assume that $A^{i}=A=1$ and that $\tau=(1-\theta)^{-1}$. Other steady state relations are given by,

$$
\begin{gathered}
Y=(1-\kappa)^{-\frac{\sigma}{\psi+\sigma}}, C=(1-\kappa)^{\frac{\psi}{\psi+\sigma}}, G=\kappa(1-\kappa)^{-\frac{\sigma}{\psi+\sigma}} \\
N=(1-\kappa)^{-\frac{\sigma}{\psi+\sigma}}, W / P=1 \text { and } R=\beta^{-1} .
\end{gathered}
$$

We use quarterly data from EMU countries (OECD Economic Outlook quarterly database) posterior to the German reunification, i.e. ranging from 1992 to 2006. Aggregates are converted in the same currency and we focus on the following seasonally adjusted series: GDP (without investment), private consumption, employment, GDP deflator, trade balance and current account balance (as a percentage of GDP). We also take into account the evolution of the average nominal short-term interest rate in the EMU.

We build two regions based on the levels of nominal rigidities of EMU countries (see Benigno, 2004). Table 1 indicates the percentage of goods prices in the consumer price index changing every month in EMU countries (data are borrowed from Alvarez et al., 2006). We consider that countries in which less than $15 \%$ of CPI goods prices change every month belong to the group of high nominal rigidities and countries in which more than $15 \%$ of CPI goods prices change every month belong to the group of low nominal rigidities. Consequently, in the first group (region $h$ in the model), we have Germany, Spain and Italy and in the second group (region $f$ in the model), we have all remaining countries. ${ }^{5}$

Once both regions of the monetary union are defined, we aggregate series given the relative time-varying weights of countries in terms of GDP in the region. Inflation rates are computed using GDP deflators. Finally, we take the log of GDP, consumption and employment and detrend all series using the HP-filter. We estimate the model using a large sample of second order moments. We focus on three types of moment: standard deviations (absolute or relative to standard deviation of output), first-order autocorrelations and cross-correlations. Standard deviations and autocorrelations concern all

4 The $\log -$ linear approximation of the model is presented in Table A.1 in the appendix.

5 Austria, Greece and Ireland are not taken into account because data are unavailable or not reliable. 
Table 1

Nominal rigidities in the EMU

\begin{tabular}{lccc}
\hline & Region & $\begin{array}{c}\text { \% goods in the CPI } \\
\text { changing prices every month }\end{array}$ & $\begin{array}{c}\text { \% of country's GDP } \\
\text { in the EMU GDP }\end{array}$ \\
\hline Germany & $h$ & 13.5 & 29.1 \\
France & $f$ & 23.9 & 21.6 \\
Italy & $h$ & 10.0 & 17.7 \\
Spain & $h$ & 13.3 & 11.0 \\
Netherlands & $f$ & 16.2 & 6.4 \\
Belgium & $f$ & 17.6 & 3.7 \\
Luxembourg & $f$ & 23.0 & - \\
Finland & $f$ & 20.3 & 2.0 \\
Portugal & $f$ & 21.1 & 1.8 \\
\hline
\end{tabular}

variables and cross-correlations are those of output with private consumption, output with hours and private consumption with hours.

Some parameters of the model are calibrated. We set $\beta=0.988$, which corresponds to an annual real interest rate of $4.7 \%$, consistent with the average real interest rate over the corresponding period in the EMU. Following Rotemberg and Woodford (1997), the elasticity of substitution between varieties is $\theta=7$, implying an average $16-17 \%$ steady state mark-up (compensated at the equilibrium by the optimal subsidy). The average share of public spending in the GDP is set to $\kappa=0.25$ (see Galí and Monacelli, 2008). The elasticity of substitution between intermediate goods is $\phi=1.5$ (see Hairault, 2002). Finally, we calibrate parameters of the nominal interest rate rule using standard values for the smoothing parameter $\rho_{r}=0.7$ and for the feedback coefficient on aggregate inflation $\varphi=1.5$ (see Gerlach and Schnabel, 2000).

Other parameters are estimated. The results of the estimation are reported in Table 2. The test allowed by over-identifying conditions implies a $0.8035 \%$ p-value, which indicates that the model is not rejected by the data.

Table 2

Estimated parameters

\begin{tabular}{cccccccc}
\hline$\psi$ & $\sigma$ & $\alpha$ & $\gamma$ & $\chi$ & $\eta^{h}$ & $\eta^{f}$ & $\mu$ \\
$7.0776^{*}$ & $1.8111^{*}$ & $0.2675^{*}$ & $0.0509^{*}$ & $0.0009^{*}$ & $0.5023^{*}$ & $0.5024^{*}$ & $2.9344^{*}$ \\
\hline$\rho_{a}$ & $\rho_{g}$ & $s t d\left(\zeta_{a, t}\right)$ & $s t d\left(\zeta_{g, t}\right)$ & & $J-$ stat & Ov. Id. Stat. & $p$ - value \\
$0.9525^{*}$ & $0.8862^{*}$ & $0.0079^{*}$ & $0.0099^{*}$ & & 10.0875 & $\chi^{2}(16)$ & 0.8035 \\
\hline *: $99 \%$ significant & & & & & &
\end{tabular}


Parameter values are consistent with most estimates or calibrations reported in the literature and are significant. The inverse of the Frisch elasticity $\psi$ is equal to 7.08 and lies on the upper bound of the range put forth by Canzoneri, Cumby and Diba (2006). This value is consistent with a sluggish response of labour supply to various shocks in the EMU. The intertemporal elasticity of substitution of private consumption is $\sigma=1.81$, close to standard values (see Benigno, 2004). This parameter governs both the intensity of the transmission of monetary policy through the sensitivity of consumption to the real interest rate and the arbitrage between leisure and consumption. Home bias parameters are $\gamma=0.051$ and $\alpha=0.27$ and determine the degree of trade openness of intermediate and final goods markets. These values are consistent with those found in Faia (2007) and with standard openness measures calculated using EMU data. The estimation of $\chi=0.0009$ is not far from Schmitt-Grohé and Uribe (2003). It implies that households have to pay an average annual $0.36 \%$ interest rate premium to access financial markets. Nominal rigidities parameters are very close since $\eta^{h}=0.5024$ and $\eta^{f}=0.5023$. Our estimation is lower than usual estimations, as in Clarida, Galí and Gertler (1998), but matches the values put forth in Alvarez et al. (2006). Finally, parameters governing shocks' processes are $\rho_{a}=0.9525, \rho_{g}=0.8862, \operatorname{std}\left(\zeta_{a, t}\right)=0.79 \%$ and $\operatorname{std}\left(\zeta_{g, t}\right)=0.99 \%$. These estimations are consistent with most values found in the $\mathrm{RBC}$ literature.

\section{Dynamic properties}

In this section we study the dynamic properties of the economy when facing asymmetric productivity and public spending shocks.

Figure 1 plots the Impulse Response Functions (IRFs) to a positive unit productivity shock in the home country.

Output rises in both countries, while more substantially in country $h$, peeking at $0.7 \%$ for a $1 \%$ productivity shock. In country $h$, the remaing of productivity gains is used to reduce the labour effort, about $0.25 \%$ on impact. This effect arises because the wealth effect dominates in models with separable utility functions and without physical capital. The wealth effect is reinforced by the $0.17 \%$ drop of the PPI inflation in the home country.

The transmission of the shock in country $f$ draws both on trade flows and monetary policy. While agents in country $h$ sustain higher production and consumption levels, they generate intermediate and final trade flows within the monetary union, which induces a positive reaction of the output in country $f$ of about $0.3 \%$ on impact. The common monetary policy also favors a positive transmission. By reacting to aggregate inflation, the central bank lowers its equilibrium nominal interest rate, which induces an increase of aggregate consumption and output in country $f$. The supply shock in country $h$ thus translates into a positive demand shock in country $f$, which generates 
Fig. 1. IRFs to a unit productivity shock in country $h$
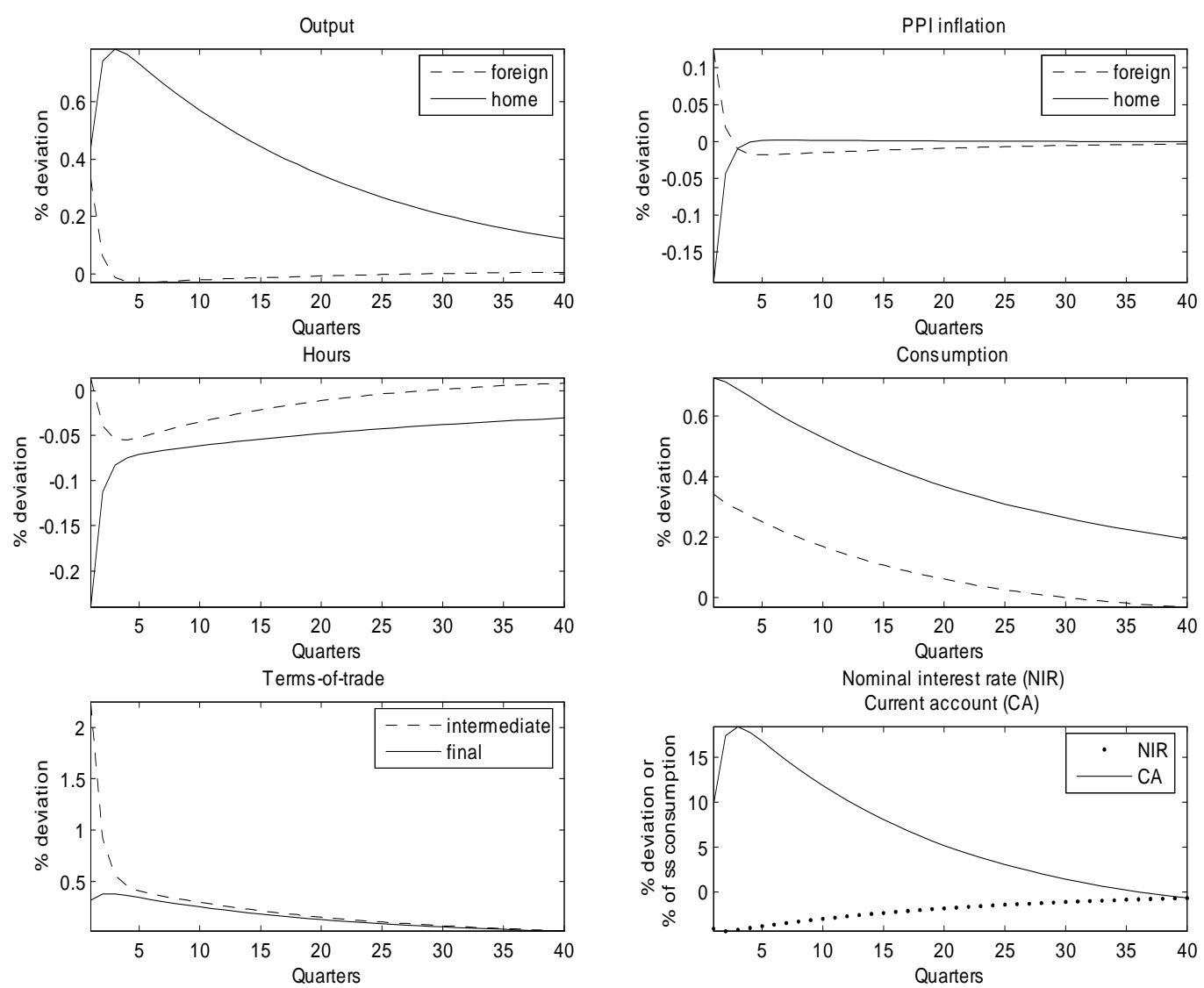

some PPI inflation, peeking at $0.12 \%$ on impact and returning quickly to the steady state.

Since wages and production prices drop in country $h$ and rise in country $f$, both intermediate and final terms-of-trade improve in country $h$. Final goods prices are sluggish, which implies an undershooting of final terms-of-trade with respect to the fluctuation of intermediate terms-of-trade. Finally, agents in country $h$ accumulate net foreign assets, implying an improvement of the current account peeking at $16-17 \%$ of steady state consumption on impact.

Figure 2 plots the IRFs to a positive unit public spending shock in the home country.

Output increases of $0.15 \%$ on impact in country $h$, implying a rise of both home and foreign labor supply, required to sustain the demanded quantity of final goods in country $h$. Private consumption drops steadily in both countries. The drop attains $0.13 \%$ in country $h$, because of the crowding-out effect and because Ricardian equivalence holds. The drop is more gentle in country $f$, reaching $0.08 \%$ on impact. Since global demand drops in country $f$, output clearly falls of $0.07 \%$ on impact while returning 
Fig. 2. IRFs to a unit public spending shock in country $h$
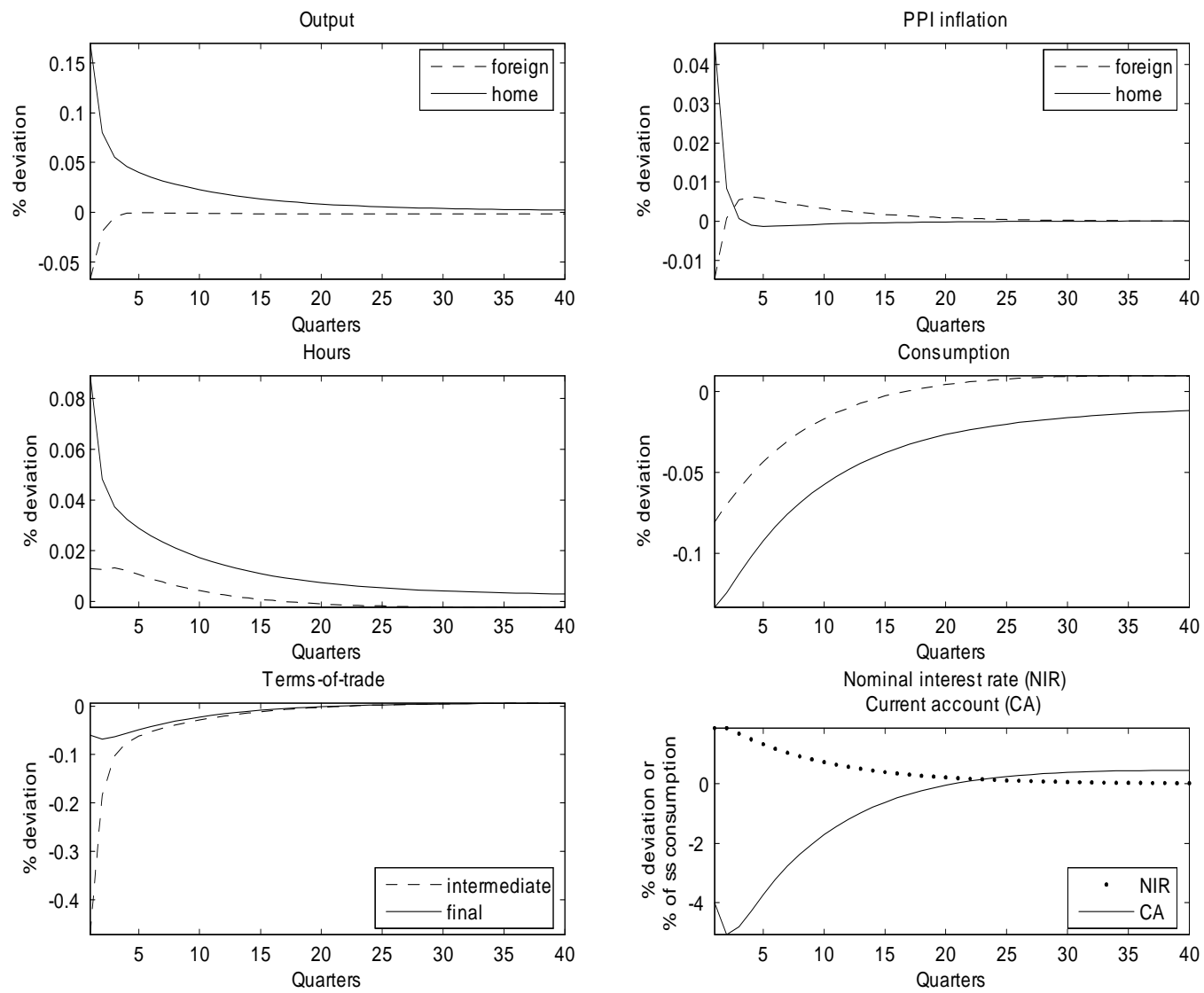

very quickly to the steady state. Mechanisms behind the negative transmission of a public spending shocks in country $h$ build on a traditional beggar-thy-neighbor effect and highlight the role of home bias in public spending in a first approach. However, this effect also relies $(i)$ on the fall of private consumption in country $h$, implying a drop of country $h$ imports from country $f$ and $(i i)$ on the increase of nominal interest rate implied by the reaction of the central bank to the inflation of country $h$. The positive demand shock in country $h$ thus translates into a negative demand shock in country $f$.

External adjustment implies a steady deterioration of final and intermediate terms-oftrade and an accumulation of net foreign liabilities in country $h$. The corresponding deficit of the current account peeks at $4.5-5 \%$ of steady state consumption on impact. 


\section{The welfare gains of trade integration}

In this section, we measure the welfare gains arising from a deeper horizontal of vertical trade integration in the EMU.

\subsection{Welfare indicators}

We built an explicit welfare indicator on a second-order approximation of the aggregate utility function. The welfare measure can be expressed as a discounted sum of utility flows,

$$
\omega=-\frac{q}{2} \sum_{t=0}^{\infty} \beta^{t} E_{0}\left\{\ell_{t}\right\}+t . i . p+O\left(\left\|\xi^{3}\right\|\right)
$$

where $q=(1-\kappa)^{-\frac{\sigma(1-\psi)}{\psi+\sigma}}$, t.i.p gathers terms independent of the problem and $O\left(\left\|\xi^{3}\right\|\right)$ are terms of order 3 or higher. In this expression, the instant welfare contribution $\ell_{t}$ is a quadratic function of deviations of key economic variables from their natural equilibrium path,

$$
\begin{aligned}
\ell_{t} & =\frac{\theta}{2 k^{h}}\left(\pi_{h, t}-\widetilde{\pi}_{h, t}\right)^{2}+\frac{\theta}{2 k^{f}}\left(\pi_{f, t}-\widetilde{\pi}_{f, t}\right)^{2}+\frac{\sigma+\psi(1-\kappa)}{(1-\kappa)}\left(y_{t}^{u}-\widetilde{y}_{t}^{u}\right)^{2} \\
& +(1-\kappa) \varsigma_{\alpha}\left(s_{t}-\widetilde{s}_{t}\right)^{2}+\varsigma_{\gamma}\left(\sigma_{t}-\widetilde{\sigma}_{t}\right)^{2}+\sigma(1-\kappa)\left(c_{t}^{r}-\widetilde{c}_{t}^{r}\right)^{2}+\psi\left(n_{s}^{r}-\widetilde{n}_{s}^{r}\right)^{2}
\end{aligned}
$$

where $k^{i}=\frac{\left(1-\eta^{i} \beta\right)\left(1-\eta^{i}\right)}{\eta^{i}}$. In Eq. (6), a tilde denotes the path of variables in the natural equilibrium, defined as the equilibrium under flexible prices and complete and perfectly integrated asset markets, i.e. $\eta^{h}=\eta^{f}=0$ and $\chi=0$. Superscripts $u$ and $r$ respectively stand for aggregate and relative variables.

The welfare measure $\omega$ penalizes national PPI inflation rates, the aggregate output gap, the relative consumption gap, the relative hours gap and terms-of-trade gaps. The weights affected to national inflation rates are sensitive to the degree of price stickiness through the values of $k^{i}$. Parameter $k^{i}$ depends negatively on the degree of price rigidities, so that higher weights are deferred to inflation rates when prices are stickier. We compute the consumption equivalent welfare loss. As in Beetsma and Jensen (2005), $\Psi$ is defined according to,

$$
\Psi=100 \cdot\left[\frac{(1-\beta)}{(1-\kappa)(\sigma+\psi(1-\kappa))}\left(\omega_{1}-\omega_{0}\right)\right]^{\frac{1}{2}}
$$

where $\omega_{0}$ measures the welfare for a given reference situation. $\Psi$ converts the welfare gains associated to a pareto-superior equilibrium $\omega_{1}$ into a sizable yardstick in terms of permanent increase of consumption for an unchanged work effort. 


\subsection{Baseline scenario}

Running simulations using the baseline estimation, Table 3 contrasts the welfare gains or losses $(\Psi)$ arising from a deeper horizontal or vertical trade integration consistent with the evidence documented by Baldwin (2006), i.e. a $10 \%$ increase of $\alpha$ or $\gamma$. The table also details the evolution of the volatility of variables entering in the welfare loss function.

Table 3

The welfare gains of a $10 \%$ deeper horizontal $(\alpha)$ or vertical $(\gamma)$ trade integration

\begin{tabular}{lcccccccc}
\hline & & \multicolumn{7}{c}{ Standard deviation (\%) } \\
\cline { 2 - 9 } & $\Psi(\%)$ & $\widehat{\pi}_{h, t}$ & $\widehat{\pi}_{f, t}$ & $\widehat{y}_{t}^{u}$ & $\widehat{s}_{t}$ & $\widehat{\sigma}_{t}$ & $\widehat{c}_{t}^{r}$ & $\widehat{n}_{t}^{r}$ \\
\hline Baseline & - & 0.188 & 0.190 & 0.047 & 0.731 & 1.925 & 1.002 & 0.308 \\
\hline$\alpha=0.2397$ & -1.81 & 0.186 & 0.187 & 0.047 & 0.665 & 1.963 & 1.008 & 0.311 \\
Variation $(\%)$ & - & -1.50 & -1.49 & 0.00 & -9.12 & 1.98 & 0.64 & 1.17 \\
\hline$\gamma=0.0704$ & 13.92 & 0.185 & 0.187 & 0.047 & 0.721 & 1.786 & 0.996 & 0.300 \\
Variation(\%) & - & -1.53 & -1.54 & -0.00 & -1.38 & -7.20 & -0.56 & -2.54 \\
\hline
\end{tabular}

Note: variables with a hat denote deviations from natural equilibrium

On one hand, a $10 \%$ increase of $\gamma$ generates large welfare gains, equivalent to an average $13.92 \%$ increase of permanent consumption. The overall volatility of terms entering the loss function is clearly dampened. When vertical trade increases, the composition of final goods produced becomes more similar, which implies that shocks affecting the production process of intermediate goods asymmetrically have more similar effects on output and marginal costs. This mechanism also contributes to lower the PPI national inflation rates, as illustrated by the new keynesian Phillips curves. If marginal costs, the driving force behind the PPI inflation rates, are more correlated, then the PPI inflation rates are affected in the same way. The adequacy of the common monetary policy to national inflation rates and business cycles increases, which improves its effectiveness and reduces the volatility of national inflation rates. Finally, by the same reasoning, the volatility of intermediate terms-of-trade, relative hours and relative consumptions gaps is reduced, which translates into aggregate welfare gains.

On the other hand, in the baseline scenario, a $10 \%$ increase of horizontal trade measured by a $10 \%$ increase of $\alpha$, implies an average welfare loss equivalent to a $1.81 \%$ fall of permanent consumption.

A close examination of volatilities shows that the distance of national inflation rates and final terms-of-trade from their natural equilibrium path is clearly reduced (respectively by $1.50 \%$ in average and $9.12 \%$ ), which has welfare improving consequences. Since the composition of the CPI inflation rates and private consumption bundles becomes more similar, for a given monetary policy rule, monetary policy becomes more effective and its ability to stabilize national PPI inflation rates increases. These lower national PPI 
inflation rates result in a lower pressure on final terms-of-trade, which clearly reduces their volatility.

However, while external adjustment relies less on the final terms-of-trade, the volatility of the current account is enhanced, which leads to welfare losses that more than compensate the previous welfare gains. These losses are imputable to the increased distance of hours and intermediate terms-of-trade to their natural level. The fact that agents use the current account more intensively to adjust asymmetric shocks implies that labor supplies and wages become less correlated and that the volatility of intermediate terms-of-trade, based on relative wages, increases.

These effects arise because debtor (resp. creditor) households need to improve (resp. lower) their labor supply in order to increase (resp. decrease) their earnings and repay their debts (resp. lower their savings) in the medium run. The intensity of this effect clearly depends on the level of costs levied by financial intermediaries, that increases the sensitivity of consumptions, labor efforts and equilibrium wages to variations of net foreign assets or liabilities. A corollary to the increased volatility of relative labor efforts and intermediate terms-of-trade is the increased volatility of relative consumptions. Because the composition of consumptions becomes more similar, relative consumptions should be less volatile. However, the consequences of the greater use of the current account dampen this first effect, implying that relative consumptions gaps are more volatile, which is also costly in terms of welfare.

Summing up, an increase in horizontal trade reduces the intensity of inefficiencies caused by nominal rigidities but magnifies inefficiencies related to the imperfect integration of financial markets. For the baseline scenario, welfare losses are higher than welfare gains.

Our results match those of other studies that quantitify the welfare gains associated to the reduction of various distortions in the economy. Canzoneri et al. (2006) estimate that the welfare costs of nominal inertia can reach $4 \%$ to $5 \%$, mostly depending on the degree of persistence in the economy. In our model, the value of the Frisch elasiticty is low, the assumption of imperfect risk-sharing adds an important source of persistence, and the estimated persistence of shocks is quite high. The overall persistence is thus important and, consistently with Canzoneri et al. (2006), nominal inertia is quite costly in terms of welfare in our model. Several studies also quantify the welfare gains of financial markets integration, building on higher risk-sharing and consumption smoothing. For example, Van Wincoop (1999) finds that the welfare gains from risksharing range from $1 \%$ to more than $7 \%$ of consumption. Those welfare gains could actually be much higher according to previous studies using alternative methods to measure financial markets integration (see Lewis, 1996). More recently, Demyanyk and Volosovych (2008) document that the welfare gains of financial markets integration range from $1 \%$ of permanent consumption for EMU members to more than $8 \%$ for new European Union members. In our model, both sources of welfare losses (nominal inertia and imperfect risk-sharing) are combined and to yield important welfare losses. 
As suggested by Dotsey and Ireland (1996), this combination of various frictions may actually result in important welfare losses.

\subsection{Sensitivity analysis}

We investigate the robustness of our results to a wide range of parameters variations. The simulations have been run to evaluate the sensitivity of our results to the asymmetry in the pattern of nominal rigidities. Since these simulations show that asymmetries in the pattern of nominal rigidities do not play a significant role in generating our results, they are not reported but available.

Figure 3 reports the sensitivity of welfare gains or losses associated to a $10 \%$ increase in horizontal trade to different variations in the set of structural parameters.

Fig. 3. Sensitivity of the welfare gains or losses of a $10 \%$ increase in horizontal trade
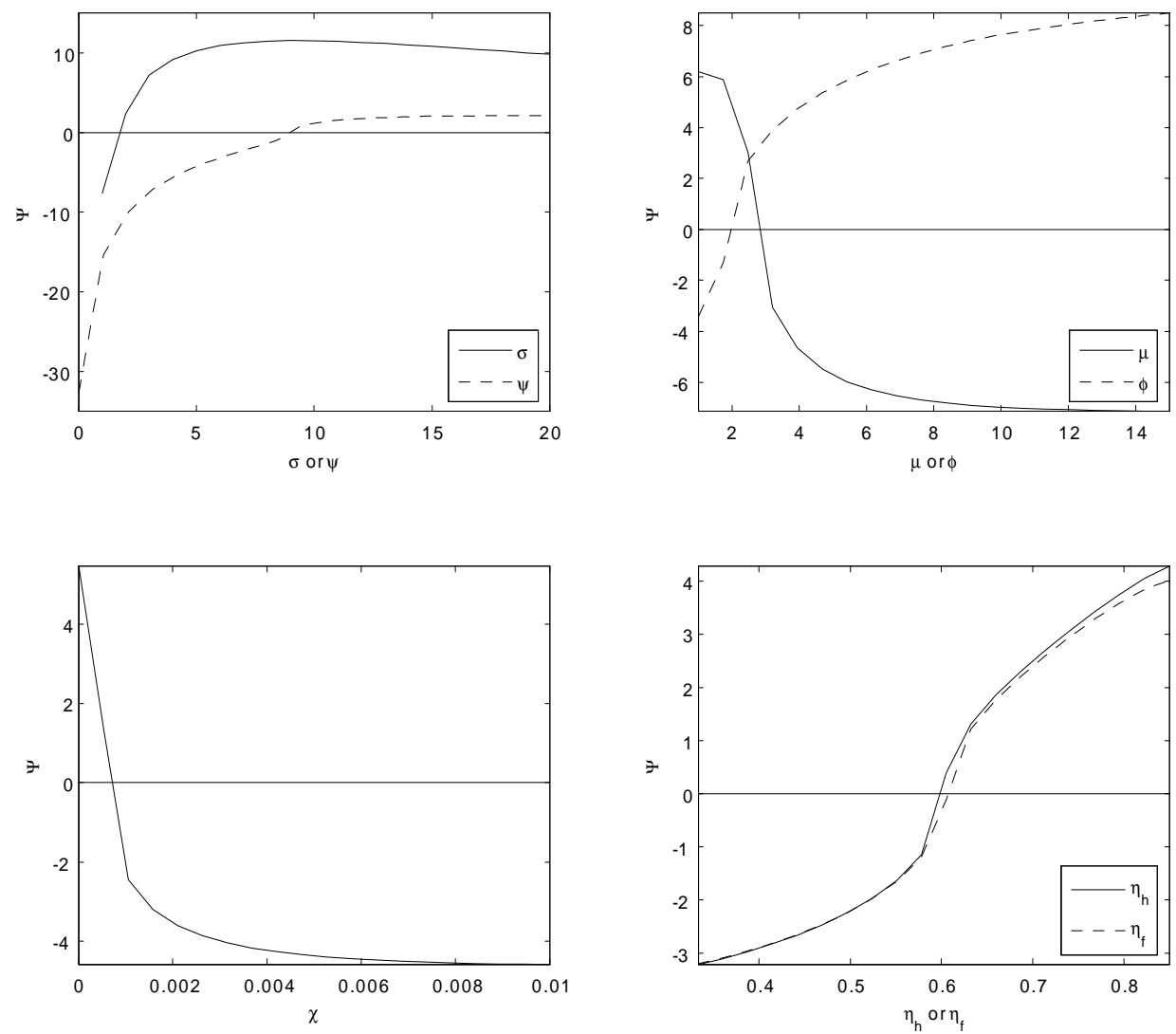

Figure 3 one more time highlights the interaction between two effects when horizontal trade integration increases: $(i)$ welfare gains related to the lower costs of nominal rigidities and $(i i)$ welfare losses caused by the increased volatility of the current account. 
Depending on parametrization, the overall welfare effect of horizontal trade integration is either positive or negative.

When portfolio management costs $(\chi)$ fall under a certain threshold, between $0.09 \%$ and $0.1 \%$, or when nominal rigidities are beyond 0.6 , horizontal trade integration generates welfare gains. This is the case either because the enhanced volatility of the current account become less costly or because the reduction of national PPI inflation rates generates higher welfare gains. These results clearly show that frictions on financial markets are a key assumption to generate our results. This assumption introduces welfare losses related to imperfect risk-sharing among members of the monetary union. The sensitivity analysis reveals that small frictions $(\chi=0.09 \%$ implies that households have to pay an average $0.36 \%$ annual interest rate premium to access financial markets) are sufficient to mitigate the welfare gains of lower inflation rates when horizontal trade increases. One shall also notice that the welfare gains of lower national inflation rates clearly surpass welfare losses when nominal rigidities parameters take standard values of the literature (around 0.7-0.75).

The sensitivity of welfare gains/losses to variations of the elasticity of substitution between intermediate or final goods also illustrates the mechanism behind welfare gains or losses. As the elasticity of substitution between final goods $(\mu)$ increases, changes in the volatility of final terms-of-trade implied by an enhanced horizontal trade integration are lower. In the equilibrium, the volatility of PPI inflation rates is thus reduced, while the impact of $\mu$ on the volatility of the current account is clearly positive (see the equation governing net foreign assets dynamics in Table A.1). Welfare gains related to lower national inflation rates are thus dampened, while welfare losses caused by the increased volatility of the current account increase. As a consequence, net welfare gains of horizontal trade integration depend negatively on the elasticity of substitution between final goods. On the contrary, as the elasticity of substitution between intermediate goods $(\phi)$ increases, intermediate terms-of-trade are less required to fluctuate to reach the equilibrium on intermediate goods markets, ceteris paribus. As a consequence, the rise of the volatility of intermediate terms-of-trade, relative hours and relative consumptions gaps are reduced when horizontal trade increases, which has a positive impact on welfare gains.

Finally, the sensitivity of welfare gains to the inverse of the Frisch elasticity $(\psi)$ and the risk-aversion parameter $(\sigma)$ is also investigated. When the intertemporal elasticity of labor supply $(\psi)$ increases, the volatility of hours decreases in the equilibrium. Since welfare losses related to financial frictions depend on the response of labor supply - as documented in the previous subsection, lower responses of labor supplies imply lower overall welfare losses or higher overall welfare gains when horizontal trade integration increases. The effect of the risk-aversion parameter is somehow surprising. The riskaversion parameter governs the willingness of households to smooth their consumption over time when undergoing unexpected asymmetric shocks, which is associated with an increased use of financial markets, and should lead to higher welfare losses. However, Figure 3 tells us that these aspects are more than compensated by the drop of the 
volatility of terms-of-trade and of national inflation rates. Risk-aversion is thus found to have a positive impact on the welfare gains generated by an increase in horizontal trade integration.

Second, figure 4 reports the sensitivity of welfare gains or losses associated to a $10 \%$ increase in vertical trade to different variations in the set of structural parameters.

Fig. 4. Sensitivity of the welfare gains or losses of a $10 \%$ increase in vertical trade
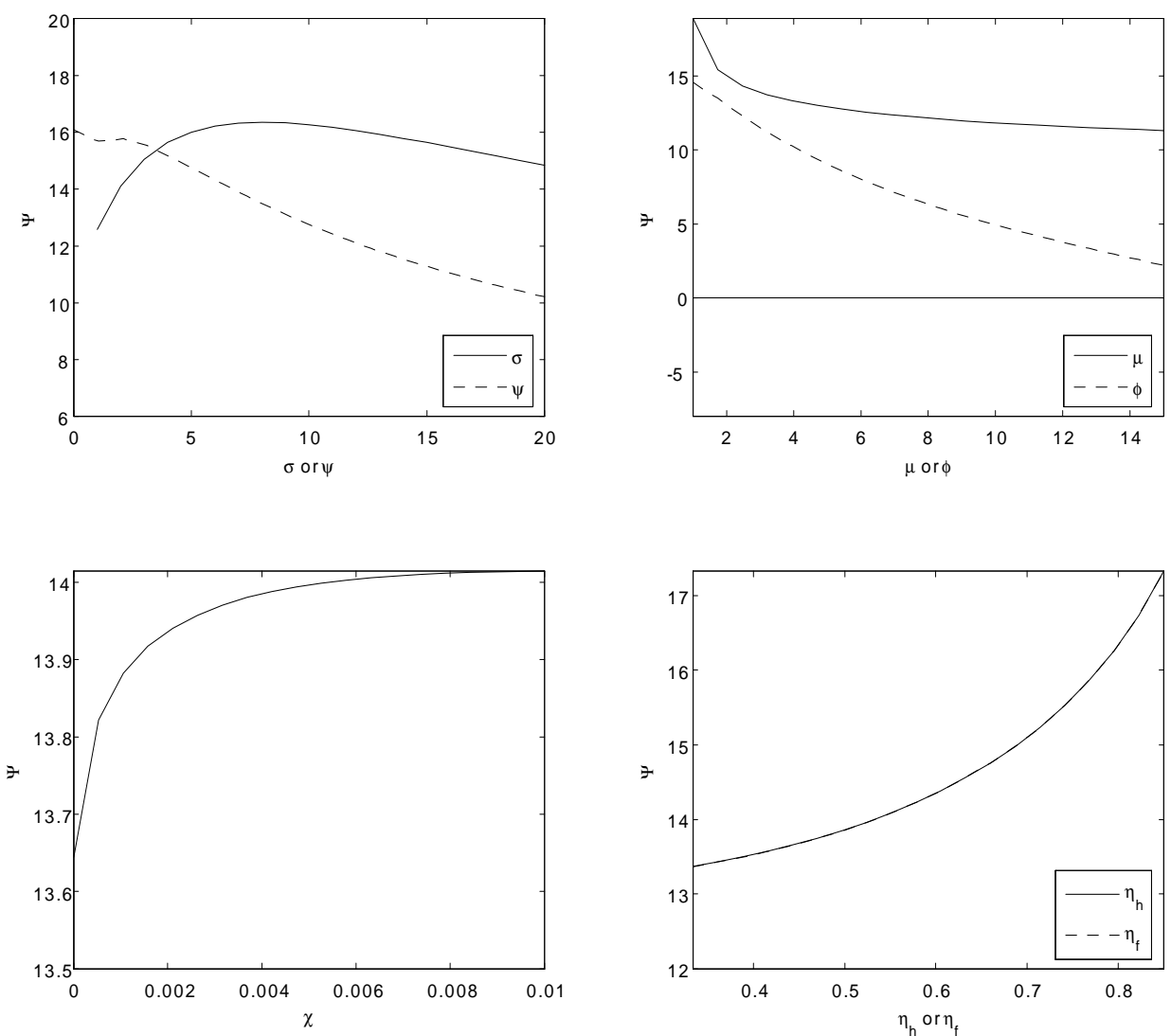

Welfare gains generated by a 10\% deeper vertical trade integration are clearly increasing with the degree of nominal rigidities $(\eta)$, since the reduction of national inflation rates is both enhanced and more weighted in the loss function.

These gains are bearly sensitive to the level of portfolio management costs $(\chi)$, which confirms that financial markets do not play an important role when trade integration is vertical.

The welfare gains of a deeper vertical trade integration also clearly decrease with the degree of substitutability between goods. While the decrease is important when the substitutability of final goods $(\mu)$ increases (from more than $15 \%$ of permanent consumption when $\mu=1$ to $10 \%$ when $\mu=15$ ), welfare gains decline even more when 
the substitutability of intermediate goods $(\phi)$ increases (from $14 \%$ of permanent consumption when $\phi=1$ to $0 \%$ when $\phi=15)$. In general, higher substitutability lowers the required variations of terms-of-trade volatility when vertical trade increases. As a consequence, as substitutability increases, changes in intermediate and final termsof-trade volatility become very small when trade integration increases, which impacts negatively on welfare gains. This effect is much stronger for the substitutability between intermediate goods because nominal rigidities bear on final goods prices while intermediate goods prices are flexible. When the substitutability between intermediate goods increases, the volatility of intermediate terms-of-trade gaps tend to become unaffected and the impact of vertical trade integration on welfare vanishes. Because final terms-of-trade are staggered, the welfare gains of vertical trade integration do not completely fade away.

Finally, an increase of the intertemporal elasticity of substitution of labor supply $(\psi)$ has a negative impact on the welfare gains of vertical trade integration for most plausible values $(\psi>1)$. In the case of vertical trade integration, the volatility of the current account decreases. The softening effect of an increase of $\psi$ on the volatility of labor supplies thus affects welfare gains in the opposite direction. Indeed, in the equilibrium, higher values of $\psi$ imply lower volatilities of hours worked, which slows down the process of reduction of regional differences in hours and lowers welfare gains of vertical trade integration.

\section{Conclusion}

This paper shows that horizontal and vertical trade integration have different outcomes in terms of welfare in a monetary union characterized by business cycles asymmetries and inflation differentials. In both cases, a deeper trade integration reduces inflation differentials by favoring a better diffusion of shocks from one country to an another, through increased trade flows. This increased macroeconomic interdependence helps the common monetary policy to be in line with national situations. Equilibrium national inflation rates decrease, and imply that trade integration thus generates welfare gains.

However, horizontal trade integration improves the volatility of the current account while vertical trade integration reduces the overall need for external adjustment in case of asymmetric shocks. As a consequence, horizontal trade integration implies welfare losses that might exceed the previous welfare gains.

For the baseline estimation presented in this paper, horizontal trade integration produces welfare losses equivalent to an average 1.8\% drop of permanent consumption and vertical trade integration generates welfare gains that amount to an average $13.9 \%$ of permanent consumption. However, an extensive sensitivity analysis indicates that the relative importance of financial markets frictions and nominal rigidities plays a key role in the pattern of welfare gains or losses. 
The main conclusion of the paper is that financial frictions, as well as their interactions with real and nominal rigidities should carefully be taken into account when analyzing business cycles asymmetries in open economies and/or monetary unions.

\section{References}

Alvarez, L. J., Dhyne, E., Dias, D., Hoffmann, J., Jonker, N., Lünnemann, H. L. B. P., Rumler, F., Veronese, G. \& Vilmunen, J. (2006), 'Price Setting in the Euro Area: Some Stylized Facts from Individual Consumer Price Data', Journal of the European Economic Association 4(2-3), 575-84.

Baldwin, R. (2006), 'The Euro's Trade Effects', ECB Working Paper No594.

Beetsma, R. M. W. J. \& Jensen, H. (2005), 'Monetary and Fiscal Policy Interactions in a Micro-founded Model of Monetary Union', Journal of International Economics 67(2), 320-52.

Benigno, P. (2004), 'Optimal Monetary Policy in a Currency Area', Journal of International Economics 63(2), 293-320.

Benigno, P. \& Woodford, M. (2005), 'Inflation Stabilization and Welfare: The Case of a Distorted Steady State', Journal of the European Economic Association 3(6), 1185-1236.

Camacho, M., Perez-Quiros, G. \& Saiz, L. (2006), 'Are European Business Cycles Close Enough to Be Just One?', Journal of Economics Dynamics and Control 30(9-10), 16871706.

Canzoneri, M., Cumby, R. \& Diba, B. (2006), 'The Cost of Nominal Inertia in NNS Models', Journal of Money, Credit and Banking. Forthcoming.

Carré, M. \& Collard, F. (2003), 'Monetary Union: A Welfare-based Approach', European Economic Review 47(3), 521-52.

Clarida, R., Galí, J. \& Gertler, M. (1998), 'Monetary Policy Rules in Practice. Some International Evidence', European Economic Review 42, 1033-1067.

Corsetti, G. (2006), 'Openness and the Case for Flexible Exchange Rates', Research in Economics 60(1), 1-21.

Demyanyk, Y. \& Volosovych, V. (2008), 'Gains from Financial Integration in the European Union: Evidence for New and Old Members', Journal of International Money and Finance 27, 277-94.

Dotsey, M. \& Ireland, P. (1996), 'The Welfare Cost of Inflation in General Equilibrium', Journal of Monetary Economics 37(1), 29-47.

Faia, E. (2007), 'Finance and International Business Cycles', Journal of Monetary Economics 54(4), 1018-34.

Galí, J. \& Monacelli, T. (2005), 'Monetary Policy and Exchange Rate Volatility in a Small Open Economy', Review of Economic Studies 72, 707-34. 
Galí, J. \& Monacelli, T. (2008), 'Optimal Monetary and Fiscal Policy in a Currency Union', Journal of International Economics . Forthcoming.

Gerlach, S. \& Schnabel, G. (2000), 'The Taylor Rule and Interest Rates in the EMU Area', Economics Letters 67, 165-171.

Hairault, J. O. (2002), 'Labor-market Search and International Business Cycles', Review of Economic Dynamics 5, 535-58.

Hansen, G. (1982), 'Large Sample Properties of Generalized Method of Moments estimators', Econometrica 50(4), 1029-1054.

Lane, P. R. (2006), 'The Real Effects of the Euro', Journal of Economic Perspectives $\mathbf{2 0}(4), 47-66$.

Lewis, K. K. (1996), Consumption, Stock Returns, and the Gains from International Risksharing, Technical report, NBER Working Paper Nº5410.

Peersman, G. \& Smets, F. R. (1999), 'The Taylor Rule, a Useful Monetary Benchmark for the Euro Area?', International Finance 2(1), 85-116.

Ricci, L. A. (1997), A Model of an Optimum Currency Area, Technical report, IMF Working Paper $\mathrm{N}^{\circ} 97 / 76$.

Romer, D. (1993), 'Openness and Inflation: Theory and Evidence', The Quarterly Journal of Economics 108(4), 869-903.

Rotemberg, J. \& Woodford, M. (1997), An Optimization-Based Econometric Framework for the Evaluation of Monetary Policy, in B. S. Bernanke \& J. J. Rotemberg, eds, 'NBER Macroeconomics Annual'.

Rudebusch, G. \& Svensson, L. (1998), Policy Rules for Inflation Targeting, NBER Working Paper $\mathrm{N}^{o} 6512$.

Schmitt-Grohé, S. \& Uribe, M. (2003), 'Closing Small Open Economy Models', Journal of International Economics 61(1), 163-85.

Taylor, J. (1993), 'Discretion versus Policy Rules in Practice', Carnegie Rochester Conference Series on Public Policy 39, 195-214.

Van Wincoop, E. (1999), 'How Big are Potential Welfare Gains from International Risksharing?', Journal of International Economics 47, 109-35.

Woodford, M. (2003), 'Optimal Interest-rate Smoothing', Review of Economic Studies 70(4), 861-86. 


\section{APPENDIX}

\section{A Log-linear approximation of the model}

Table A.1

A $\log$-linear approximation of the model

Euler equations and labor supply

$\sigma E_{t}\left\{c_{t+1}^{h}-c_{t}^{h}\right\}=r_{t+1}-E_{t}\left\{(1-\alpha) \pi_{h, t+1}+\alpha \pi_{f, t+1}\right\}-\chi(1-\kappa)^{\frac{\psi}{\psi+\sigma}} b_{t+1}^{h}$

$\sigma E_{t}\left\{c_{t+1}^{f}-c_{t}^{f}\right\}=r_{t+1}-E_{t}\left\{(1-\alpha) \pi_{f, t+1}+\alpha \pi_{h, t+1}\right\}+\chi(1-\kappa)^{\frac{\psi}{\psi+\sigma}} b_{t+1}^{h}$

$\psi n_{t}^{h}+\sigma c_{t}^{h}=w_{t}^{h}-p_{h, t}-\alpha s_{t} \quad \psi n_{t}^{f}+\sigma c_{t}^{f}=w_{t}^{f}-p_{f, t}+\alpha s_{t}$

Inflation and terms-of-trade

$\pi_{h, t}=\beta E_{t}\left\{\pi_{h, t+1}\right\}+\frac{\left(1-\eta^{h} \beta\right)\left(1-\eta^{h}\right)}{\eta^{h}}\left((1-\gamma)\left(w_{t}^{h}-a_{t}^{h}\right)+\gamma\left(w_{t}^{f}-a_{t}^{f}\right)-p_{h, t}\right)$

$\pi_{f, t}=\beta E_{t}\left\{\pi_{f, t+1}\right\}+\frac{\left(1-\eta^{f} \beta\right)\left(1-\eta^{f}\right)}{\eta^{f}}\left((1-\gamma)\left(w_{t}^{f}-a_{t}^{f}\right)+\gamma\left(w_{t}^{h}-a_{t}^{h}\right)-p_{f, t}\right)$

$\pi_{h, t}=p_{h, t}-p_{h, t-1} \quad \pi_{f, t}=p_{f, t}-p_{f, t-1}$

$s_{t}-s_{t-1}=\pi_{f, t}-\pi_{h, t} \quad \sigma_{t}=w_{t}^{f}-w_{t}^{h}+a_{t}^{h}-a_{t}^{f}$

Goods market clearing

$y_{t}^{h}=(1-\kappa)\left((1-\alpha) c_{t}^{h}+\alpha c_{t}^{f}+2 \alpha \mu(1-\alpha) s_{t}\right)+\kappa g_{t}^{h}$

$y_{t}^{f}=(1-\kappa)\left((1-\alpha) c_{t}^{f}+\alpha c_{t}^{h}-2 \alpha \mu(1-\alpha) s_{t}\right)+\kappa g_{t}^{f}$

$a_{t}^{h}+n_{t}^{h}=(1-\gamma) y_{t}^{h}+\gamma y_{t}^{f}+2 \phi \gamma(1-\gamma) \sigma_{t}$

$a_{t}^{f}+n_{t}^{f}=(1-\gamma) y_{t}^{f}+\gamma y_{t}^{h}-2 \phi \gamma(1-\gamma) \sigma_{t}$

Current account

$b_{t+1}^{h}-b_{t}^{h}=\delta b_{t}^{h}+\alpha\left[c_{t}^{f}-c_{t}^{h}+(2 \mu(1-\alpha)-1) s_{t}\right]+\frac{\gamma}{1-\kappa}\left[y_{t}^{f}-y_{t}^{h}+(2 \phi(1-\gamma)-1) \sigma_{t}\right]$

Interest rate rule

$r_{t+1}=\rho_{r} r_{t}+\beta \varphi\left(\frac{1}{2} \pi_{h, t}+\frac{1}{2} \pi_{f, t}\right)$ 


\section{B The welfare loss function}

The welfare criterion writes

$$
\begin{aligned}
\omega_{T} & =\sum_{s=t}^{s=T} \beta^{s-t} E_{t}\left\{\int_{0}^{1}\left[\frac{1}{2} U_{s}^{h}(j)+\frac{1}{2} U_{s}^{f}(j)\right] d j\right\} \\
& =\sum_{s=t}^{s=T} \beta^{s-t} E_{t}\left\{\int_{0}^{1}\left[\frac{1}{2} U_{s}^{h}\left(C_{s}^{h}(j), N_{s}^{h}(j)\right)+\frac{1}{2} U_{s}^{f}\left(C_{s}^{f}(j), N_{s}^{f}(j)\right)\right] d j\right\} \\
& =\sum_{s=t}^{s=T} \beta^{s-t} E_{t}\left\{\int_{0}^{1}\left[U_{C, s}^{u}(j)-U_{N, s}^{u}(j)\right] d j\right\},
\end{aligned}
$$

where, after using the symmetry among agents,

$$
\begin{aligned}
& U_{C, t}^{u}(j)=U_{C, t}^{u}=\frac{1}{2(1-\rho)}\left(C_{t}^{h}\right)^{1-\rho}+\frac{1}{2(1-\rho)}\left(C_{t}^{f}\right)^{1-\rho} \\
& U_{N, t}^{u}(j)=U_{N, t}^{u}=\frac{1}{2(1+\psi)}\left(N_{t}^{h}\right)^{1+\psi}+\frac{1}{2(1+\psi)}\left(N_{t}^{f}\right)^{1+\psi} .
\end{aligned}
$$

We compute welfare derivations through a second order approximation of variables to their steady state values and for second order expressions of shocks equal to zero, i.e. $\left[a_{t}^{i}\right]^{2}=\left[g_{t}^{i}\right]^{2}=0$. Before approximating, we need to state,

$$
\begin{gathered}
\frac{1}{2}\left[\left[c_{t}^{h}\right]^{2}+\left[c_{t}^{f}\right]^{2}\right]=\left[c_{t}^{u}\right]^{2}+\left[c_{t}^{r}\right]^{2}, \\
\frac{1}{2}\left[\left[n_{t}^{h}\right]^{2}+\left[n_{t}^{f}\right]^{2}\right]=\left[n_{t}^{u}\right]^{2}+\left[n_{t}^{r}\right]^{2} .
\end{gathered}
$$

A second order approximation to $U_{C, t}^{u}$ writes,

$$
U_{C, t}^{u} \simeq \frac{C^{1-\rho}}{1-\rho}+C^{1-\rho}\left[c_{t}^{u}+\frac{1-\rho}{2}\left(\left[c_{t}^{u}\right]^{2}+\left[c_{t}^{r}\right]^{2}\right)\right]+O\left(\left\|\xi^{3}\right\|\right) .
$$

A second order approximation to $U_{N, t}^{u}$ writes,

$$
U_{N, t}^{u} \simeq \frac{N^{1+\psi}}{1+\psi}+N^{1+\psi}\left[n_{t}^{u}+\frac{1+\psi}{2}\left(\left[n_{t}^{u}\right]^{2}+\left[n_{t}^{r}\right]^{2}\right)\right]+O\left(\left\|\xi^{3}\right\|\right)
$$


Recalling that $\left[a_{t}^{i}\right]^{2}=0$, a second order approximation of intermediate goods markets gives,

$$
\begin{aligned}
n_{t}^{h}+\frac{1}{2}\left[a_{t}^{h}+n_{t}^{h}\right]^{2} & =(1-\gamma)\left(y_{t}^{h}+\gamma \sigma_{t}+\frac{1}{2}\left[y_{t}^{h}+\gamma \sigma_{t}\right]^{2}+d p_{t}^{h}\right) \\
& +\gamma\left(y_{t}^{f}+(1-\gamma) \sigma_{t}+\frac{1}{2}\left[y_{t}^{f}+(1-\gamma) \sigma_{t}\right]^{2}+d p_{t}^{f}\right) \\
& + \text { t.i.p }+O\left(\left\|\xi^{3}\right\|\right), \\
n_{t}^{f}+\frac{1}{2}\left[a_{t}^{f}+n_{t}^{f}\right]^{2} & =(1-\gamma)\left(y_{t}^{f}-\gamma \sigma_{t}+\frac{1}{2}\left[y_{t}^{f}-\gamma \sigma_{t}\right]^{2}+d p_{t}^{f}\right) \\
& +\gamma\left(y_{t}^{h}-(1-\gamma) \sigma_{t}+\frac{1}{2}\left[y_{t}^{h}-(1-\gamma) \sigma_{t}\right]^{2}+d p_{t}^{h}\right) \\
& + \text { t.i.p }+O\left(\left\|\xi^{3}\right\|\right),
\end{aligned}
$$

where t.i.p stands for terms that are independent of the problem, and,

$$
d p_{t}^{i}=\frac{\theta}{2} \operatorname{var}\left(p_{i, t}\right),
$$

implying that $\left[d p_{t}^{i}\right]^{2} \in O\left(\left\|\xi^{3}\right\|\right)$. Combining the last two expressions, we get,

$$
\begin{aligned}
& n_{t}^{u}+\frac{1}{2}\left[n_{t}^{u}\right]^{2}+\frac{1}{2}\left[n_{t}^{r}\right]^{2}+\frac{1}{2} a_{t}^{h} n_{t}^{h}+\frac{1}{2} a_{t}^{f} n_{t}^{f}= \\
& y_{t}^{u}+\frac{1}{2}\left[y_{t}^{u}\right]^{2}+\frac{1}{2}\left[y_{t}^{r}\right]^{2}+\frac{1}{2} \gamma(1-\gamma)\left[\sigma_{t}\right]^{2} \\
&+\frac{\theta}{4} \operatorname{var}\left(p_{h, t}\right)+\frac{\theta}{4} \operatorname{var}\left(p_{f, t}\right) \\
&+t . i \cdot p+O\left(\left\|\xi^{3}\right\|\right) .
\end{aligned}
$$

Combining with (B.1), we get,

$$
\begin{aligned}
U_{N, t}^{u} & \simeq N^{1+\psi}\left\{y_{t}^{u}+\frac{1}{2}\left[y_{t}^{u}\right]^{2}+\frac{1}{2}\left[y_{t}^{r}\right]^{2}-\frac{1}{2} a_{t}^{h} n_{t}^{h}-\frac{1}{2} a_{t}^{f} n_{t}^{f}\right. \\
& +\frac{\gamma(1-\gamma)}{2}\left[\sigma_{t}\right]^{2}+\frac{\theta}{4} \operatorname{var}\left(p_{h, t}\right)+\frac{\theta}{4} \operatorname{var}\left(p_{f, t}\right) \\
& \left.+\frac{\psi}{2}\left[n_{t}^{u}\right]^{2}+\frac{\psi}{2}\left[n_{t}^{r}\right]^{2}\right\}+t . i . p+O\left(\left\|\xi^{3}\right\|\right) .
\end{aligned}
$$


Now turning to $U_{C, t}^{u}$, we compute a second order approximation to final goods markets conditions, while recalling that $\left[g_{t}^{i}\right]^{2}=0$,

$$
\begin{aligned}
y_{t}^{h}+\frac{1}{2}\left[y_{t}^{h}\right]^{2} & =(1-\alpha)(1-\kappa)\left(c_{t}^{h}+\alpha s_{t}+\frac{1}{2}\left[c_{t}^{h}+\alpha s_{t}\right]^{2}\right) \\
& +\alpha(1-\kappa)\left(c_{t}^{f}+(1-\alpha) s_{t}+\frac{1}{2}\left[c_{t}^{f}+(1-\alpha) s_{t}\right]^{2}\right) \\
& + \text { t.i.p }+O\left(\left\|\xi^{3}\right\|\right), \\
y_{t}^{f}+\frac{1}{2}\left[y_{t}^{f}\right]^{2} & =(1-\alpha)(1-\kappa)\left(c_{t}^{f}-\alpha s_{t}+\frac{1}{2}\left[c_{t}^{f}-\alpha s_{t}\right]^{2}\right) \\
& +\alpha(1-\kappa)\left(c_{t}^{h}-(1-\alpha) s_{t}+\frac{1}{2}\left[c_{t}^{h}-(1-\alpha) s_{t}\right]^{2}\right) \\
& + \text { t.i.p }+O\left(\left\|\xi^{3}\right\|\right),
\end{aligned}
$$

which allows to deduce,

$$
\begin{aligned}
& y_{t}^{u}+\frac{1}{2}\left[y_{t}^{u}\right]^{2}+\frac{1}{2}\left[n_{t}^{r}\right]^{2}=(1-\kappa)\left(c_{t}^{u}+\frac{1}{2}\left[c_{t}^{u}\right]^{2}+\frac{1}{2}\left[c_{t}^{r}\right]^{2}\right) \\
& \frac{(1-\kappa) \alpha(1-\alpha)}{2}\left[s_{t}\right]^{2}+t . i . p+O\left(\left\|\xi^{3}\right\|\right),
\end{aligned}
$$

or,

$$
\begin{aligned}
c_{t}^{u}+\frac{1}{2}\left[c_{t}^{u}\right]^{2}+\frac{1}{2}\left[c_{t}^{r}\right]^{2} & =\frac{1}{(1-\kappa)}\left(y_{t}^{u}+\frac{1}{2}\left[y_{t}^{u}\right]^{2}+\frac{1}{2}\left[y_{t}^{r}\right]^{2}\right) \\
& -\frac{\alpha(1-\alpha)}{2}\left[s_{t}\right]^{2}+\text { t.i.p }+O\left(\left\|\xi^{3}\right\|\right),
\end{aligned}
$$

$U_{C, t}^{u}$ becomes,

$$
\begin{aligned}
U_{C, t}^{u} & \simeq C^{1-\rho}\left\{\frac{1}{1-\kappa}\left(y_{t}^{u}+\frac{1}{2}\left[y_{t}^{u}\right]^{2}+\frac{1}{2}\left[y_{t}^{r}\right]^{2}\right)\right. \\
& \left.-\frac{1}{2} \alpha(1-\alpha)\left[s_{t}\right]^{2}-\frac{\rho}{4}\left[c_{t}^{h}\right]^{2}-\frac{\rho}{4}\left[c_{t}^{f}\right]^{2}\right\} \\
& + \text { t.i.p }+O\left(\left\|\xi^{3}\right\|\right) .
\end{aligned}
$$


Collecting terms, we get,

$$
\begin{aligned}
U_{t}^{u} & =U_{C, t}^{u}-U_{N, t}^{u} \simeq C^{1-\rho}\left\{\frac{1}{1-\kappa}\left(y_{t}^{u}+\frac{1}{2}\left[y_{t}^{u}\right]^{2}+\frac{1}{2}\left[y_{t}^{r}\right]^{2}\right)\right. \\
& \left.-\frac{\alpha(1-\alpha)}{2}\left[s_{t}\right]^{2}-\frac{\rho}{2}\left[c_{t}^{u}\right]^{2}-\frac{\rho}{2}\left[c_{t}^{r}\right]^{2}\right\} \\
& -N^{1+\psi}\left\{y_{t}^{u}+\frac{1}{2}\left[y_{t}^{u}\right]^{2}+\frac{1}{2}\left[y_{t}^{r}\right]^{2}+\frac{\gamma(1-\gamma)}{2}\left[\sigma_{t}\right]^{2}\right. \\
& +\frac{\theta}{4} \operatorname{var}\left(p_{h, t}\right)+\frac{\theta}{4} \operatorname{var}\left(p_{f, t}\right)-\frac{1}{2} a_{t}^{h} n_{t}^{h}-\frac{1}{2} a_{t}^{f} n_{t}^{f} \\
& \left.+\frac{\psi}{2}\left[n_{t}^{u}\right]^{2}+\frac{\psi}{2}\left[n_{t}^{r}\right]^{2}\right\}+t . i \cdot p+O\left(\left\|\xi^{3}\right\|\right) .
\end{aligned}
$$

Using the fact that,

we get,

$$
N^{1+\psi}=\frac{Y}{A} N^{\psi}=Y C^{-\rho}=\frac{C^{1-\rho}}{(1-\kappa)},
$$

$$
\begin{aligned}
U_{t}^{u} & \simeq \frac{C^{1-\rho}}{(1-\kappa)}\left\{-\frac{(1-\kappa) \varsigma_{\alpha}}{2}\left[s_{t}\right]^{2}-\frac{\varsigma_{\gamma}}{2}\left[\sigma_{t}\right]^{2}+\frac{1}{2} a_{t}^{h} n_{t}^{h}+\frac{1}{2} a_{t}^{f} n_{t}^{f}\right. \\
& -\frac{\rho(1-\kappa)}{2}\left(\left[c_{t}^{u}\right]^{2}+\left[c_{t}^{r}\right]^{2}\right)-\frac{\psi}{2}\left(\left[n_{t}^{u}\right]^{2}+\left[n_{t}^{r}\right]^{2}\right) \\
& \left.-\frac{\theta}{4} \operatorname{var}\left(p_{h, t}\right)-\frac{\theta}{4} \operatorname{var}\left(p_{f, t}\right)\right\}+ \text { t.i.p }+O\left(\left\|\xi^{3}\right\|\right),
\end{aligned}
$$

where $\varsigma_{\gamma}=\gamma(1-\gamma) \geq 0$ and $\varsigma_{\alpha}=\alpha(1-\alpha) \geq 0$. Recalling,

$$
\begin{aligned}
n_{t}^{u} & =y_{t}^{u}-a_{t}^{u}, \\
c_{t}^{u} & =\frac{y_{t}^{u}-\kappa g_{t}^{u}}{(1-\kappa)},
\end{aligned}
$$

we get,

$$
\begin{aligned}
U_{t}^{u} & \simeq \frac{C^{1-\rho}}{(1-\kappa)}\left\{-\frac{(1-\kappa) \varsigma_{\alpha}}{2}\left[s_{t}\right]^{2}-\frac{\varsigma_{\gamma}}{2}\left[\sigma_{t}\right]^{2}-\frac{\theta}{4} \operatorname{var}\left(p_{h, t}\right)-\frac{\theta}{4} \operatorname{var}\left(p_{f, t}\right)\right. \\
& -\frac{\rho}{2(1-\kappa)}\left[\left[y_{t}^{u}\right]^{2}-2 \kappa y_{t}^{u} g_{t}^{u}\right]-\frac{\rho(1-\kappa)}{2}\left[c_{t}^{r}\right]^{2} \\
& \left.-\frac{\psi}{2}\left[\left[y_{t}^{u}\right]^{2}-2 y_{t}^{u} a_{t}^{u}\right]-\frac{\psi}{2}\left[n_{t}^{r}\right]^{2}+\frac{1}{2} a_{t}^{h} n_{t}^{h}+\frac{1}{2} a_{t}^{f} n_{t}^{f}\right\}+t . i . p+O\left(\left\|\xi^{3}\right\|\right) .
\end{aligned}
$$

Recalling that,

$$
\widetilde{y}_{t}^{u}=\frac{(1-\kappa)(\psi+1)}{\psi(1-\kappa)+\rho} a_{t}^{u}+\frac{\kappa \rho}{\psi(1-\kappa)+\rho} g_{t}^{u},
$$


the welfare simplifies to,

$$
\begin{aligned}
U_{t}^{u} & \simeq \frac{C^{1-\rho}}{(1-\kappa)}\left\{-\frac{(1-\kappa) \varsigma_{\alpha}}{2}\left[s_{t}\right]^{2}-\frac{\varsigma_{\gamma}}{2}\left[\sigma_{t}\right]^{2}-\frac{\theta}{4} \operatorname{var}\left(p_{h, t}\right)-\frac{\theta}{4} \operatorname{var}\left(p_{f, t}\right)\right. \\
& -\frac{\rho+\psi(1-\kappa)}{2(1-\kappa)}\left[y_{t}^{u}-\widetilde{y}_{t}^{u}\right]^{2}-y_{t}^{u} a_{t}^{u}+\frac{1}{2} a_{t}^{h} n_{t}^{h}+\frac{1}{2} a_{t}^{f} n_{t}^{f} \\
& \left.-\frac{\rho(1-\kappa)}{2}\left[c_{t}^{r}\right]^{2}-\frac{\psi}{2}\left[n_{t}^{r}\right]^{2}\right\}+t . i \cdot p+O\left(\left\|\xi^{3}\right\|\right) .
\end{aligned}
$$

Simplifying cross products with,

$$
\begin{aligned}
\frac{1}{2} a_{t}^{h} n_{t}^{h}+\frac{1}{2} a_{t}^{f} n_{t}^{f} & =n_{t}^{u} a_{t}^{u}+n_{t}^{r} a_{t}^{r} \\
& =y_{t}^{u} a_{t}^{u}+n_{t}^{r} a_{t}^{r}+\text { t.i.p }
\end{aligned}
$$

we get,

$$
\begin{aligned}
& U_{t}^{u} \simeq \frac{C^{1-\rho}}{(1-\kappa)}\left\{-\frac{(1-\kappa) \varsigma_{\alpha}}{2}\left[s_{t}\right]^{2}-\frac{\varsigma_{\gamma}}{2}\left[\sigma_{t}\right]^{2}-\frac{\theta}{4} \operatorname{var}\left(p_{h, t}\right)-\frac{\theta}{4} \operatorname{var}\left(p_{f, t}\right)\right. \\
& \left.-\frac{\rho+\psi(1-\kappa)}{2(1-\kappa)}\left[y_{t}^{u}-\widetilde{y}_{t}^{u}\right]^{2}+n_{t}^{r} a_{t}^{r}-\frac{\rho(1-\kappa)}{2}\left[c_{t}^{r}\right]^{2}-\frac{\psi}{2}\left[n_{t}^{r}\right]^{2}\right\} \\
& +t . i . p+O\left(\left\|\xi^{3}\right\|\right) \text {. }
\end{aligned}
$$

Using,

$$
\begin{gathered}
\widetilde{\sigma}_{t}=\frac{2 \kappa \psi(1-2 \gamma)}{\varpi_{\gamma}} g_{t}^{r}-\frac{2(1+\psi)}{\varpi_{\gamma}} a_{t}^{r}, \\
\widetilde{s}_{t}=\frac{2 \kappa \psi(1-2 \gamma)^{2}}{\varpi_{\gamma}} g_{t}^{r}-\frac{2(1+\psi)(1-2 \gamma)}{\varpi_{\gamma}} a_{t}^{r}, \\
\widetilde{c}_{t}^{r}=\frac{2(1+\psi)(1-2 \gamma)(1-2 \alpha)}{2 \rho \varpi_{\gamma}} a_{t}^{r}-\frac{2 \kappa \psi(1-2 \gamma)^{2}(1-2 \alpha)}{2 \rho \varpi_{\gamma}} g_{t}^{r}, \\
\widetilde{n}_{t}^{r}=\frac{2\left(\varpi_{\alpha}(1-2 \gamma)^{2}+2 \varsigma_{\gamma}\right)-1}{\varpi_{\gamma}} a_{t}^{r}+\frac{\kappa(1-2 \gamma)}{\varpi_{\gamma}} g_{t}^{r}
\end{gathered}
$$

where $\varpi_{\gamma}=1+2 \psi\left(\varpi_{\alpha}(1-2 \gamma)^{2}+2 \varsigma_{\gamma}\right)$, and decomposing $n_{t}^{r} a_{t}^{r}$,

$$
\begin{aligned}
& n_{t}^{r} a_{t}^{r}=\frac{(1+\psi)}{\varpi_{\gamma}} n_{t}^{r} a_{t}^{r}-\frac{\psi \kappa(1-2 \gamma)}{\varpi_{\gamma}} g_{t}^{r} n_{t}^{r} \\
& +g_{t}^{r} \underbrace{\left(\frac{\varpi_{\gamma}-(1+\psi)}{\varpi_{\gamma}} a_{t}^{r}+\frac{\psi \kappa(1-2 \gamma)}{\varpi_{\gamma}}\right)}_{\psi \widetilde{n}_{t}^{r}} n_{t}^{r} .
\end{aligned}
$$


Using the expressions of $n_{t}^{r}$ and $y_{t}^{r}$,

$$
\begin{aligned}
n_{t}^{r} a_{t}^{r} & =(1-\kappa) c_{t}^{r} \underbrace{(\underbrace{(1-2 \gamma)(1-2 \alpha)(1+\psi)}_{\widetilde{s}_{t}} a_{\gamma}^{r}-\frac{\psi \kappa(1-2 \gamma)^{2}(1-2 \alpha)}{\varpi_{\gamma}} g_{t}^{r})}_{\rho \widetilde{c}_{t}^{r}} \\
& -(1-\kappa) \varsigma_{\alpha} s_{t} \underbrace{\left(\frac{2(1+\psi)(1-2 \gamma)}{\varpi_{\gamma}} a_{t}^{r}-\frac{2 \psi \kappa(1-2 \gamma)^{2}}{\varpi_{\gamma}} g_{t}^{r}\right)}_{-\widetilde{\sigma}_{t}} \\
& -\varsigma_{\gamma} \sigma_{t} \underbrace{\left(\frac{2(1+\psi)}{\varpi_{\gamma}} a_{t}^{r}-\frac{2 \kappa \psi(1-2 \gamma)}{\left.\varpi_{t}^{r}\right)}\right.}_{\varpi_{\gamma}} \\
& +\psi \widetilde{n}_{t}^{r} n_{t}^{r} .
\end{aligned}
$$

Simplifying,

$$
n_{t}^{r} a_{t}^{r}=\rho(1-\kappa) \widetilde{c}_{t}^{r} c_{t}^{r}+\psi \widetilde{n}_{t}^{r} n_{t}^{r}+\varsigma_{\gamma} \widetilde{\sigma}_{t} \sigma_{t}+(1-\kappa) \varsigma_{\alpha} \widetilde{s}_{t} s_{t},
$$

and plugging into the welfare expression,

$$
\begin{aligned}
& U_{t}^{u} \simeq \frac{C^{1-\rho}}{(1-\kappa)}\left\{-\frac{(1-\kappa) \varsigma_{\alpha}}{2}\left[\widehat{s}_{t}\right]^{2}-\frac{\varsigma_{\gamma}}{2}\left[\widehat{\sigma}_{t}\right]^{2}-\frac{\theta}{4} \operatorname{var}\left(p_{h, t}\right)-\frac{\theta}{4} \operatorname{var}\left(p_{f, t}\right)\right. \\
& \left.-\frac{\rho+\psi(1-\kappa)}{2(1-\kappa)}\left[\widehat{y}_{t}^{u}\right]^{2}-\frac{\rho(1-\kappa)}{2}\left[\widehat{c}_{t}^{r}\right]^{2}-\frac{\psi}{2}\left[\widehat{n}_{t}^{r}\right]^{2}\right\} \\
& + \text { t.i.p }+O\left(\left\|\xi^{3}\right\|\right) \text {. }
\end{aligned}
$$

where $\widehat{x}_{t}=x_{t}-\widetilde{x}_{t}$. Actualizing and summing among periods, we get,

$$
\omega_{T}=\sum_{s=t}^{s=T} \beta^{s-t} E_{t}\left\{U_{s}^{u}\right\} .
$$

Following Woodford (2003), we know that,

$$
\sum_{s=t}^{s=T} \beta^{s-t} \operatorname{var}\left(p_{i, s}\right)=\sum_{s=t}^{s=T} \beta^{s-t} \frac{\pi_{i, s}^{2}}{k^{i}},
$$

where $k^{i}=\frac{\left(1-\eta^{i} \beta\right)\left(1-\eta^{i}\right)}{\eta^{i}}$ which yields the final form of the welfare function,

$$
\begin{aligned}
\omega_{T}= & -\frac{C^{1-\rho}}{2(1-\kappa)} \sum_{s=t}^{s=T} \beta^{s-t} E_{t}\left\{(1-\kappa) \varsigma_{\alpha}\left[\widehat{s}_{t}\right]^{2}+\varsigma_{\gamma}\left[\widehat{\sigma}_{t}\right]^{2}+\frac{\theta}{2 \varphi^{h}} \pi_{h, t}^{2}+\frac{\theta}{2 \varphi^{f}} \pi_{f, t}^{2}\right. \\
& \left.+\frac{\rho+\psi(1-\kappa)}{(1-\kappa)}\left[\widehat{y}_{t}^{u}\right]^{2}+\rho(1-\kappa)\left[\widehat{c}_{t}^{r}\right]^{2}+\psi\left[\widehat{n}_{t}^{r}\right]^{2}\right\}+t . i . p+O\left(\left\|\xi^{3}\right\|\right) .
\end{aligned}
$$

where $\varsigma_{\gamma}=\gamma(1-\gamma) \geq 0, \varsigma_{\alpha}=\alpha(1-\alpha) \geq 0, \varphi^{i}=\frac{\left(1-\eta^{i} \beta\right)\left(1-\eta^{i}\right)}{\eta^{i}}$, and where t.i.p gathers terms independent of the problem and $O\left(\left\|\xi^{3}\right\|\right)$ terms of order 3 or higher. 